Goldschmidt 2021 Abstract

https://doi.org/10.7185/gold2021.3977

\section{Quantification of $\mathrm{Li}$ content in organic matrices by Secondary Ion Mass Spectrometry}

ZEBADIAH TEICHERT, MAITRAYEE BOSE, PETER WILLIAMS, RICHARD HERVIG AND LYNDA WILLIAMS

Arizona State University

Presenting Author: zteicher@asu.edu

The chemical composition of materials has been shown to alter the sputtering and ionization of elements during solid-state secondary ion mass spectrometry (SIMS) measurements, necessitating the use of matrix matched standards to precisely determine elemental abundances. SIMS techniques are being employed frequently on biological and organic samples where matrix compositions are heterogeneous. It is not yet understood how variations of major matrix elements in organic molecules affects the sputtering and ionization of elements from these materials. Carbon glass and single carbon crystals have been used as standards for organic materials, but these materials lack the chemical variability of organic molecules. Therefore, as a first attempt to examine the effect of the major matrix elements of organic molecules on the sputtering and ionization of trace $\mathrm{Li}$ in the matrix, we have created ion implant standards in four different organic polymer materials and carbon glass. The matrix compositions consist primarily of C (60-75 wt.\%), O (19-33 wt.\%) and $\mathrm{H}$ (5-8 wt\%) which are representative of the bulk chemical compositions of kerogens. We performed SIMS depth profile measurements of $\mathrm{Li}$ and $\mathrm{C}$, using both $\mathrm{O}^{-}$and $\mathrm{O}_{2}^{-}$primary ion beams, to determine the Li-content calibration factors, based on $\mathrm{Li} / \mathrm{C}$ ratios, in the carbonaceous matrices (Table 1 ). We found no significant trend between the $\mathrm{Li}$ calibration factor and the $\mathrm{H}$ or $\mathrm{O}$ content of the polymer matrices measured using an $\mathrm{O}_{2}^{-}$ primary ion beam (Figure 1). However, when using an $\mathrm{O}^{-}$ primary ion beam the $\mathrm{Li}$ calibration factor is negatively correlated with the $\mathrm{O}$ content of the materials with an $\mathrm{R}^{2}$ value of 0.99 . The Li calibration factors were $23-43 \%$ smaller (higher $\mathrm{Li}$ sensitivity) for all polymers while using $\mathrm{O}^{-}$instead of $\mathrm{O}_{2}^{-}$. Importantly, we found that using a $\mathrm{Li}$ ion implant into a glassy carbon matrix provides an acceptable estimation of the Li content in an unknown carbonaceous sample. Thus, our results suggest that while calibration factors derived from measurements using an $\mathrm{O}_{2}{ }^{-}$primary beam can be directly used to quantify Li contents in unknown carbonaceous matrices, knowledge of the $\mathrm{O}$ content of unknown samples is required, when using the $\mathrm{O}^{-}$primary beam.

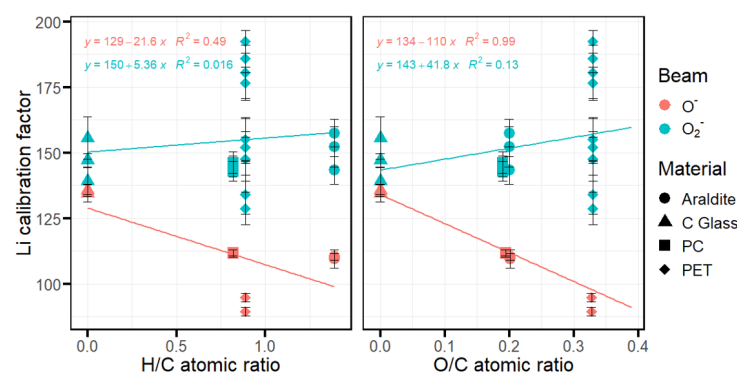

Figure 1. Scatter plots of the Li calibration factors are plotted against the $\mathrm{H} / \mathrm{C}$ and $\mathrm{O} / \mathrm{C}$ atomic ratios of polymer and $\mathrm{C}$ glass samples for two different primary beams commonly used for measurement of positive $L i$ secondary ions. Li calibration factors of different materials are within error of each other for $\mathrm{O}_{2}$ and are correlated with $\mathrm{O} / \mathrm{C}$ composition
individual analyses are plotted.

Table 1. Mean Li calibration factors

\begin{tabular}{lllllll}
\hline Sample Name & $\begin{array}{l}\mathrm{Li} \\
\text { calibration } \\
\text { factor }\left(\mathrm{O}_{2}{ }^{-}\right)\end{array}$ & $\begin{array}{l}\text { S.E. } \\
\left(2 \sigma_{\overline{\mathrm{x}}}\right)\end{array}$ & $\mathrm{n}$ & $\begin{array}{l}\text { Li calibration } \\
\text { factor }(\mathrm{O})\end{array}$ & $\begin{array}{l}\text { S.E. } \\
\left(2 \sigma_{\overline{\mathrm{x}}}\right)\end{array}$ & $\mathrm{n}$ \\
\hline Araldite 502 epoxy & 151.0 & 14.4 & 3 & 109.9 & 3.4 & 2 \\
$\begin{array}{l}\text { Lexan Polycarbonate (PC) } \\
144.7\end{array}$ & 5.9 & 3 & 111.7 & 1.5 & 2 \\
$\begin{array}{l}\text { Polyethylene teraphthalate } \\
\text { (PET) } \\
\text { Carbon Glass }\end{array}$ & 160.8 & 21.3 & 10 & 92.1 & 7.0 & 2 \\
$\begin{array}{l}\text { The mean values of Li calibration factors grouped by material and primary beam type are } \\
\text { displayed here. The S.E. in this table is the sum of the propagated S.E. errors from the individual }\end{array}$
\end{tabular}
displayed here. The S.E. in this table is the sum of the propagated S.E. errors from the individu analyses and the S.E. for each group in the table above. 